\title{
A luta pela vinculação de recursos para Saúde Pública no Brasil a partir do paradigma da universalização
}

\author{
Claudia Martiniano \\ Jordeana Davi \\ Geraldo Medeiros Júnior \\ Isabel Cristina Araújo Brandão \\ Ana Luzia Medeiros Araújo da Silva
}

\section{SciELO Books / SciELO Livros / SciELO Libros}

MARTINIANO, C., et al. A luta pela vinculação de recursos para Saúde Pública no Brasil a partir do paradigma da universalização. In DAVI, J., MARTINIANO, C., and PATRIOTA, LM., orgs.

Seguridade social e saúde: tendências e desafios [online]. 2nd ed. Campina Grande: EDUEPB, 2011. pp. 85-116. ISBN 978-85-7879-193-3. Available from SciELO Books <http://books.scielo.org>.

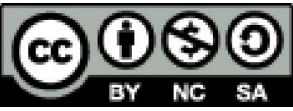

All the contents of this work, except where otherwise noted, is licensed under a Creative Commons Attribution-Non Commercial-ShareAlike 3.0 Unported.

Todo o conteúdo deste trabalho, exceto quando houver ressalva, é publicado sob a licença Creative Commons Atribuição Uso Não Comercial - Partilha nos Mesmos Termos 3.0 Não adaptada.

Todo el contenido de esta obra, excepto donde se indique lo contrario, está bajo licencia de la licencia Creative Commons Reconocimento-NoComercial-CompartirIgual 3.0 Unported. 


\title{
A luta pela vinculação de recursos para Saúde Pública no Brasil a partir do paradigma da universalização
}

\author{
Claudia Martiniano \\ Jordeana Davi \\ Geraldo Medeiros Júnior \\ Isabel Cristina Araújo Brandão \\ Ana Luzia Medeiros Araújo da Silva
}

\section{Introdução}

Este artigo tem como objetivo contribuir para uma reflexão sobre o financiamento da política de saúde a partir da Constituição Federal de 1988 (CF/1988) e das Leis 8.080 e 8.142, que garantem a saúde como direito universal e dever do Estado. Pretende resgatar as propostas acerca da vinculação de recursos para saúde no Brasil, a partir do paradigma da universalização. Tal reflexão se faz mediante a tentativa recorrente da equipe econômica em reduzir os gastos sociais em nome da política econômica neoliberal, que promove o ajuste fiscal e as manobras para a não vinculação de recursos para 
as políticas sociais, concomitantemente à criação e manutenção da Desvinculação de Recursos da União (DRU), políticas determinadas pelo grande capital.

Essa temática vem ganhando espaço nas discussões sobre a Política de Saúde, se apresentando como debate necessário à garantia da saúde como direito universal. No campo da produção científica no Brasil, no âmbito da seguridade social, destacamse as contribuições de Mota (1995; 2004; 2007), Soares (2001), Boschetti (2003; 2004; 2006), Behring (2003; 2006), Behring e Boschetti (2008), entre outros. Especificamente no setor saúde, são relevantes os estudos de Carvalho (2002), Dain (2007), Marques; Mendes (2005), entre outros. Tais contribuições apontam que as tendências do orçamento da seguridade social, nela contida a política de saúde, são profundamente determinadas pela política econômica de orientação neoliberal, no capitalismo contemporâneo.

A política de ajuste fiscal promovida pelo Governo Federal, nestes últimos anos, vem rebatendo drasticamente nas políticas sociais. Especificamente nas políticas de seguridade social (previdência, saúde e assistência social) as medidas adotadas vêm sendo mais nefastas, através de contrarreformas, uma vez que estas políticas vêm sendo alvos de críticas e responsabilizadas pelos déficits públicos do Estado brasileiro, por garantir direitos incondicionais e não-contratuais (saúde e assistência) junto com o contratual (previdência social) (CRUZ; DAVI; DANTAS, 2007). Um dos resultados deste ajuste é a restrição ou desmonte dos direitos sociais e desfinanciamento da seguridade social. Neste último tópico situaremos nossa análise.

Considerando a permanência no governo Lula da política neoliberal dos governos anteriores, mantendo inalterada a política econômica instalada desde 1990, tem prevalecido o ajuste fiscal com amplas e claras manobras do atual governo (BEHRING; SALVADOR, 2006). 


\section{A (não) implementação da Seguridade Social e o financiamento da política de saúde}

A inserção da seguridade social no sistema de proteção social brasileiro a partir da Constituição Federal de 1988 (CF/88) significou a garantia, ao conjunto da população brasileira, de direitos relativos à saúde, assistência social e previdência social. Os princípios que guiaram estas modificações, segundo Marques; Mendes (2005, p. 159, grifo nosso) foram:

[...] ampliação da cobertura para segmentos até então desprotegidos; eliminação das diferenças de tratamento entre trabalhadores rurais e urbanos; implementação da gestão descentralizada nas políticas de saúde e assistência; participação dos setores interessados no processo decisório e no controle da execução das políticas; definição de mecanismos de financiamento mais seguros e estáveis; e garantia de um volume suficiente de recursos para a implementação das políticas contempladas pela proteção social, entre outros objetivos.

Embora a estrutura da seguridade tenha a orientação daquelas que conformam o Estado de Bem-Estar nos países desenvolvidos, na particularidades brasileira, marcadamente no que diz respeito à desigualdade social e fragilidade do processo de publicização do Estado, a adoção do conceito de seguridade social, segundo Mota (2004), não alcançou êxito na universalização de benefícios sociais.

Além disso, para a autora, esta significativa ampliação da seguridade tem um custo que é institucionalizar tanto a inclusão dos trabalhadores anteriormente excluídos do sistema de proteção social por meio de programas assistenciais, quanto a expulsão dos 
trabalhadores assalariados, com maior poder aquisitivo, para o mercado de serviços, a exemplo da mercantilização da saúde e da previdência. E ainda afirma que

[...] esse processo foi um dos determinantes das tendências atuais da seguridade social brasileira, criando condições objetivas e subjetivas para uma fragmentação das necessidades e dos interesses mediatos e imediatos dos trabalhadores no que diz respeito aos mecanismos de proteção social (MOTA, 2004, p. 8).

A CF/88 determinou, ainda, a formulação de um orçamento próprio para a seguridade social, com recursos específicos, diferenciados daqueles que financiam as demais políticas de governo, que é denominado de Orçamento Fiscal. O Orçamento da Seguridade Social (OSS) é formado por contribuições sociais e deveria responder pelo financiamento exclusivo das políticas componentes da seguridade. Já o Orçamento Fiscal é formado por impostos e responde pelo financiamento do conjunto de responsabilidades do governo, a exemplo de gastos com pessoal, pagamentos de encargos da dívida pública, educação, habitação, agricultura etc.

$\mathrm{Na}$ composição do financiamento do OSS, sem vinculação de receitas específicas para cada política integrante da Seguridade Social, a CF/88, no seu artigo 195, determinou que

a seguridade social será financiada por toda a sociedade $[\ldots]$ mediante recursos provenientes dos orçamentos da União, dos Estados, do Distrito Federal e dos municípios, e das seguintes contribuições sociais:

I - do empregador, da empresa e da entidade a ela equiparada, na forma da lei, incidentes sobre:

a) a folha de salários e demais rendimentos do trabalho pagos ou creditados, a qualquer título, 
à pessoa física que lhe preste serviço, mesmo sem vínculo empregatício;

b) a receita ou o faturamento;

c) o lucro;

II - do trabalhador e dos demais segurados da previdência social, não incidindo contribuição sobre a aposentadoria e pensão concedidas pelo regime geral de previdência social, de que trata o art. 201;

III - sobre a receita de concurso de prognósticos;

IV - do importador de bens e serviços do exterior, ou de quem a lei a ele equiparar (BRASIL, 1988).

Nesse contexto, convém destacar que, apesar da conquista anunciada pela implantação da seguridade social, caracterizada pelo formato social-democrata pari passu à reforma do Estado brasileiro, os desdobramentos da política social vêm acompanhando, desde os anos 1990 até os dias atuais, uma onda de redimensionamento do Estado, de clara tendência reducionista de suas funções, orientadas para o mercado (BEHRING; BOSCHETTI, 2008). Portanto, a compreensão de como vem sendo implementada a seguridade social é fundamental a qualquer análise de suas políticas integrantes, neste caso em exame, a de saúde.

A seguridade social compreendida como um espaço integrado de ações de iniciativa dos poderes públicos e da sociedade destinado a garantir os direitos relativos à saúde, à previdência e à assistência social, não vem sendo implementada como previsto. Ao contrário, do ponto de vista gerencial, as políticas concernentes a esta vêm sendo executadas de forma desarticulada, fragmentada, cujas legislações específicas traçaram rumos diferentes para as três políticas. A nosso ver, a desconstrução da ideia de seguridade social fragiliza o conjunto de direitos sociais, favorecendo a imposição 
de reformas sobre cada uma das políticas, implicando inclusive em disputas entre si. Os rebatimentos na assistência e previdência social não serão aqui discutidos.

No tocante ao OSS, convém destacar que a Constituição Federal de 1988, no Art. 55, do Ato das Disposições Constitucionais Transitórias (ADCT), definiu que "até que seja aprovada a Lei de Diretrizes Orçamentárias, trinta por cento, no mínimo, do orçamento da seguridade social, excluído o seguro-desemprego, serão destinados ao setor de saúde." Este percentual valia para o ano de 1989, cuja Lei de Diretrizes Orçamentárias (LDO) já estava elaborada. Nos anos seguintes, ou seja, de 1990 a 1993 ficou mantido o percentual de 30\% nas respectivas leis orçamentárias federais, mas, ainda que constasse, esse percentual foi descumprido. A situação piorou a partir de 1994, quando esse percentual deixou de ser citado na LDO. Segundo Carvalho (2007), ainda que a legislação seja mandatária, o que ocorreu foi a não implementação do orçamento da seguridade. Sendo assim, este percentual não foi cumprido e nos anos pós-Constituição chegou no máximo a $20 \%$, com destaque para o pior percentual, em 1992, no governo Collor de Mello, de 14\%.

Além disso, o autor ressalta que em 1993, arbitrariamente, o Ministro da Previdência Social, deixa de repassar para a saúde cerca de 250 milhões de reais provenientes da Contribuição sobre a Folha de Salários de Trabalhadores. Tal situação obrigou o Ministério da Saúde a pedir empréstimos ao Fundo de Amparo ao Trabalhador (FAT). Como observam Marques e Mendes (2005), esta lei foi sistematicamente descumprida em todos os governos que se seguiram à Constituição de 1988, o que se configura no primeiro entrave do financiamento da saúde, já que o investimento em saúde anualmente vem sendo inferior ao montante previsto do OSS. A destinação anual para a saúde do OSS pode ser observada na tabela 1 abaixo. 
Tabela 1 - Recursos liquidados da Seguridade Social no Fundo Nacional de Saúde (FNS) (Em bilhões)

\begin{tabular}{|c|c|c|c|}
\hline Anos & Total Pago Seguridade Social (A) & FNS (B) & \%B/A \\
\hline 2000 & 130.885 .365 .080 & 18.464 .660 .141 & 14,10 \\
\hline 2001 & 151.445 .666 .178 & 20.657 .322 .442 & 13,64 \\
\hline 2002 & 175.471 .998 .237 & 23.166 .845 .267 & 13,20 \\
\hline 2003 & 197.948 .411 .715 & 24.899 .631 .046 & 12,57 \\
\hline 2004 & 227.145 .544 .225 & 30.093 .752 .121 & 13,24 \\
\hline 2005 & 259.624 .334 .260 & 33.195 .811 .773 & 12,78 \\
\hline 2006 & 303.028 .000 .000 & 40.746 .200 .000 & 13,44 \\
\hline 2007 & 347.286 .000 .000 & 45.797 .200 .000 & 13,18 \\
\hline
\end{tabular}

FONTE: Boschetti e Salvador (2006) e ANFIP (2007).

Os dados acima revelam que, no período analisado houve progressiva redução da participação do FNS no OSS. A partir de 2000, observa-se uma queda dos recursos, passando de 14,1\% para 12,78\%, em 2005. Em 2006, observa-se que houve significativo aumento, que pode ser atribuído ao deslocamento das despesas do Programa Fome Zero (Bolsa Família), que eram indevidamente inseridas na programação da saúde, registrando, por fim, uma queda em 2007. Analisando o primeiro mandato do governo Lula a média de destinação foi de $13 \%$ e embora tenha se observado aumento nominal dos recursos, não acompanhou o crescimento do OSS, prevalecendo a estagnação na destinação dos recursos para a saúde enquanto observa um crescimento para a assistência social, devido, sobretudo ao pagamento de programas focalizados e seletivos. A tese central de Mota (2007, p. 129), ao analisar a tendência da seguridade social, é de que:

As políticas que integram a seguridade social brasileira, longe de formarem um amplo e articulado mecanismo de proteção, adquiriram a perversa posição de conformarem uma unidade 
contraditória: enquanto a mercantilização da saúde e da previdência precariza o acesso aos benefícios e serviços, a assistência social se amplia, transformando-se num novo fetiche de enfrentamento à desigualdade social.

A saúde, apesar de sua universalização legal/formal, combina dois mecanismos perversos: o do acesso a serviços privados como parte dos benefícios ocupacionais oferecidos pelos empregadores e o da expansão de planos de saúde populares, com oferta precária e limitada a serviços ambulatoriais de baixo custo operacional (MOTA, 2007).

Um dos princípios da seguridade é a diversidade de fontes de financiamento $^{1}$, o que implica dizer que as contribuições sociais passam a incidir não somente sobre a folha de salários, mas também sobre o faturamento e o lucro, tornando o financiamento mais redistributivo e progressivo. Entretanto, o que se observa ao longo dos anos é a especialização das fontes ao se destinar prioritariamente os recursos do FINSOCIAL para a Saúde, as contribuições sobre o lucro para Assistência Social e as contribuições incidentes sobre a folha para a Previdência. Segundo Soares (2001) esta progressiva especialização das fontes implica na fragmentação das políticas componentes da Seguridade, sujeitanda-os ao ritmo cíclico das fontes que as financiam, situação incompatível com a concepção constitucional de direitos sociais universais.

1 Para dar conta da inclusão de novos direitos como saúde universal, benefícios assistenciais não contributivos para idosos e pessoas com deficiências e expansão da Previdência Rural, as bases de financiamento forma ampliadas e diversificadas. Desta forma, a seguridade social foi incluída no orçamento fiscal da união, além da criação da Contribuição para o Financiamento da Seguridade Social (COFINS), a Contribuição sobre o Lucro Líquido (CSLL) e a Contribuição sobre Movimentações Financeiras (CPMF), sendo esta última destinada ao uso exclusivo na saúde. 
Além disso, Boschetti e Behring (2003) ressaltam que esta diversificação obriga os governos Federal, estaduais e municipais a reservar recurso do orçamento fiscal ao orçamento da seguridade. Tomados em análise, os recursos do orçamento fiscal destinados à seguridade social são ínfimos, representando baixa participação no OSS correspondendo a 0,37\% em 2005, 0,40\% em 2006 e 0,46\%, em 2007 (ANFIP, 2007). Esta alocação de recursos do orçamento fiscal para o OSS é proveniente dos encargos previdenciários da União (EPU), que correspondem aos benefícios derivados de legislação especial. São benefícios pagos pelo INSS, porém, designados por lei específica, em casos de indenizações ou reconhecimento de mérito relevante, a exemplo de anistiados, os atingidos pelo Césio 137 em Goiânia, vítimas da Talidomida do acidente da base espacial de Alcântara e da Hemodiálise de Caruaru, entre outros.

Convêm mencionar que, na fuga de recursos da seguridade, contribui, ainda, a renúncia previdenciária ${ }^{2}$ concedida a micro e pequenas empresas, através do SIMPLES; a entidades de saúde, assistência social e educação detentoras do Certificado de Entidade Beneficente de Assistência Social concedido pelo Conselho Nacional de Assistência Social, da CPMF e da Exportação da Produção Rural. A tabela 2, abaixo, contém os dados da renúncia previdenciária de 2000 a 2008.

2 A renúncia fiscal pode ocorrer sob a forma de isenção, dedução de despesas dos rendimentos tributáveis, redução de alíquotas ou mesmo incentivos fiscais. 
TABELA 2 - Estimativa de renúncias das receitas previdenciárias, segundo as programações orçamentárias - 2000 a 2008 (Em milhões de reais)

\begin{tabular}{|l|c|c|c|c|c|c|c|c|c|}
\hline \multicolumn{1}{|c|}{ Segmento } & $\mathbf{2 0 0 0}$ & $\mathbf{2 0 0 1}$ & $\mathbf{2 0 0 2}$ & $\mathbf{2 0 0 3}$ & $\mathbf{2 0 0 4}$ & $\mathbf{2 0 0 5}$ & $\mathbf{2 0 0 6}$ & $\mathbf{2 0 0 7}$ & $\mathbf{2 0 0 8}$ \\
\hline SIMPLES & $2.546,8$ & $3.705,3$ & $4.036,2$ & $4.639,8$ & $5.605,2$ & $6.467,8$ & $7.104,5$ & $4.939,7$ & $8.152,0$ \\
\hline $\begin{array}{l}\text { Entidades } \\
\text { Filantrópicas }\end{array}$ & $1.814,6$ & $2.188,7$ & $2.517,4$ & $2.937,5$ & $3.393,0$ & $3.915,2$ & $4.300,6$ & $4.751,3$ & $4.797,2$ \\
\hline $\begin{array}{l}\text { Exportação da } \\
\text { Produção Ru- } \\
\text { ral - EC 33 }\end{array}$ & 0,0 & 0,0 & $1.340,1$ & $1.777,6$ & $1.860,6$ & $2.146,9$ & $2.358,3$ & $1.970,1$ & $2.293,1$ \\
\hline CPMF & 140,0 & 180,5 & 208,3 & 221,0 & 224,9 & 259,5 & 285,0 & 476,8 & 578,0 \\
\hline $\begin{array}{l}\text { Total das } \\
\text { Renúncias }\end{array}$ & $4.501,8$ & $6.074,6$ & $8.102,0$ & $9.575,9$ & $11.083,7$ & $12.789,3$ & $14.048,4$ & $12.137,9$ & $15.820,3$ \\
\hline
\end{tabular}

FONTE: ANFIP (2007 e 2008).

Em 2008, segundo a ANFIP, estimou-se que a renúncia orçamentária chegou a $\mathrm{R} \$ 15,8$ bilhões. Tal valor corresponde a praticamente um terço do orçamento total para a saúde. Entre os beneficiados com a isenção, estão as entidades filantrópicas, muitas em essência atuando como autênticas empresas privadas, inclusive com lucros significativos. Deve-se aqui também considerar o componente regressivo da isenção, o seu alto volume e a necessidade de mais recursos para a área de saúde que, incontestavelmente, conta com necessidades potenciais dificeis de serem atendidas.

Embora a opção do Governo em deixar de arrecadar, gerando perda de receita, possa ser compreendida por alguns autores como despesa, Andreazzi; Ocké-Reis (2007), ao analisar e quantificar a renúncia fiscal do gasto das famílias e empresas com assistência à saúde no Imposto de Renda Retido na Fonte, verificaram que, somente em 2005, a renúncia fiscal foi de 2,8 milhões de reais. Para estes autores,

[...] é bastante controversa a polêmica acerca da alocação desses recursos do ponto de vista da equiidade, num quadro de custos crescentes, de um lado, e restrição fiscal de outro, na área do financiamento da atenção à saúde (Andreazzi; Ocké-Reis, 2007, p. 524). 


\section{Em nome do mercado - mais restrições aos gastos sociais a partir da década de 1990}

No início dos anos de 1990, a estratégia governamental para as políticas sociais é marcada pela formulação de nova agenda de reformas seguindo o conjunto de medidas supostamente consensuais para os países subdesenvolvidos, chamado de Consenso de Washington, e que resumia as propostas de organismos internacionais a exemplo do FMI, Banco Mundial e BIRD. O objetivo principal desta reforma é a revisão constitucional, no sentido de obstruir a consumação dos novos direitos garantidos naquela Carta, sobretudo durante o processamento da legislação complementar (CRUZ; DAVI; DANTAS, 2007). Assim, no Brasil, passa-se a adotar políticas de contenção do gasto público, com cortes lineares no gasto social.

A contra-reforma do Estado foi implantada num contexto político e econômico de ajuste fiscal, com implicações político-ideológicas que demarcam as atuais tendências de retorno à filantropia para o enfrentamento da questão social, sob a égide do ideário neoliberal, demarcando a tensão entre o econômico e o social, elementos constitutivos das sociedades capitalistas.

O setor saúde é marcado por novo declínio no financiamento público. Neste sentido, muitas propostas surgiram para o financiamento do setor, que segundo Soares (2001), foram e continuam sendo as mais controversas e polêmicas, como se destaca a seguir.

O que havia em comum em todas as propostas de revisão do financiamento do SUS era o aumento do volume de recursos e a garantia de sua estabilidade, sendo indicadas estratégias de especialização das fontes ou vinculação das fontes dentro do Orçamento da Seguridade Social. 
Nesse sentido, duas Propostas de Emendas Constitucionais chegaram ao Congresso Nacional em 1999. Uma por iniciativa do Deputado Chafick Farah (PPR/SP) que propôs que a União destinasse à saúde $18 \%$ de toda sua receita de impostos e contribuições. A outra propositura, de autoria dos Deputados Waldir Pires (PT/BA) e Eduardo Jorge (PT/SP), reitera a destinação dos 30\% do OSS para o setor saúde, e ainda $10 \%$ da receita de impostos do Tesouro Nacional, o que deveria ser seguido também pelas demais esferas de governo. Ambas as propostas são modestas em relação ao comprometimento do PIB, já que os recursos advindos da primeira equivalem a $1,8 \%$ e a segunda a $2,66 \%$ do PIB.

Dois segmentos da saúde vêm sendo propositivos e militantes na defesa do SUS e apresentaram proposta ao financiamento. O CONASEMS (Conselho Nacional de Secretários Municipais de Saúde), com preocupação centrada no processo de descentralização do SUS é solidário à proposta do Deputado Eduardo Jorge, além disso, defenderem a não especialização das fontes. Observavase que as demais propostas giram em torno da operacionalização do repasse desses recursos aos municípios.

O CONASS (Conselho Nacional de Secretários de Saúde), em sua proposta, mantém-se fiel aos princípios constitucionais e da legislação complementar, propondo a destinação de 30\% do OSS para saúde e $10 \%$ das demais esferas de governo. Indica uma reforma tributária e fiscal, sugerindo estratégias para a progressividade do sistema. De outro lado, rejeita as isenções às empresas que prestam assistência de saúde aos seus empregados do pagamento de contribuições sociais e/ou do imposto de renda, exigindo que empresas privadas reembolsem o SUS no caso de gasto de clientes destas empresas. Outra exigência do CONASS é que o Tesouro Nacional assuma com recursos fiscais a folha dos servidores ativos dos Ministérios da Saúde, da ex-Previdência e Trabalho e Bem Estar Social, além dos Encargos Previdenciários da União, antes pagos com o orçamento da seguridade social (SOARES, 2001). 
Favaret (2003) alerta que a simples vinculação não significa, por si só, a redução de desigualdades e tampouco a solução para problemas relacionados à equidade, em especial na saúde, que depende de uma complexa organização da rede e, também, de uma rede de complexas organizações, que envolve sujeitos de diferentes interesses. A vinculação apenas garante que os estados e os municípios se coloquem em um mesmo ponto de partida no que tange ao gasto com saúde e, com isso, tenham a possibilidade de ter maior autonomia na forma de executar o gasto, definindo seus modelos assistenciais próprios.

Soares (2001) observa ainda que nenhuma das propostas apresentadas parece garantir a suficiência de recursos, uma vez que suas fontes de financiamento podem sofrer modificações ao sabor de fatores como, por exemplo, a reforma tributária e o crescimento econômico. As duas propostas de emendas apresentam problemas à forma como estão postas, seja por responsabilizar a União pelo financiamento da saúde, desconsiderando as outras esferas de governo, como no caso da proposta de Chafick Farah, seja por que a proposta de Eduardo Jorge e Waldir Pires fixam percentual das contribuições sociais antes de uma definição do próprio OSS. Além disso, foram feitas alterações fundamentais pelas autoridades econômicas do governo, que conseguiram deturpar o conteúdo buscado (CARVALHO, 2008), cuja redação no momento da aprovação será discutida no tópico seguinte.

Todas estas propostas são elaboradas em meio a um contexto de ajuste fiscal. Em 1994, durante o governo de Fernando Henrique Cardoso, no contexto da contrarreforma, é criado o Fundo Social de Emergência (FSE), sob a égide do Plano de Estabilização Econômica, que nem de longe se configura um Fundo Social. Ao contrário, para Soares (2001), constitui-se na verdade a primeira estratégia de liberdade alocativa dos gastos públicos no interior do orçamento, eliminando a vinculação de receitas com claros objetivos de estabilização e zeragem do déficit público. 
O FSE vigorou nos anos de 1994 e 1995, sendo posteriormente renomeado como Fundo de Estabilização Fiscal (FEF), permanecendo em vigor de 1996 a 1999, quando foi substituído pela Desvinculação de Receitas da União (DRU), com prazo de vigência para término em 2007, sendo prorrogada até 2011. Esta estratégia permite que $20 \%$ do orçamento do governo federal fique disponível livremente para uso no pagamento do serviço das dívidas externa e interna, numa clara opção pelo saneamento da política econômica em detrimento das políticas sociais.

Embora tenha amparo legal, a DRU caminha na contramão do crescimento da economia, uma vez que retira recursos da sociedade com a finalidade de obter o superávit primário e em seguida transferi-los para o mercado. Segundo a Associação Nacional dos Auditores Fiscais de Receita Federal do Brasil (ANFIP, 2008), a seguridade tem bilhões de recursos retirados da destinação estabelecida na Constituição que são utilizados no pagamento dos juros da dívida pública federal.

Segundo dados da ANFIP, os desvios da receita de contribuições sociais por meio da DRU observado no período 2002 a 2006 foram em torno de $\mathrm{R} \$ 112$ bilhões que deveriam ser destinados às ações da Previdência, Saúde e Assistência Social, no entanto, foram desviados com o propósito de facilitar a produção de superávit primário (ANFIP, 2007). Tal situação leva Boschetti; Salvador (2006, p. 50) a afirmarem que:

Por meio da Desvinculação de Receitas da União (DRU) ocorre uma poderosa e perversa alquimia que transforma os recursos destinados ao financiamento da seguridade social em recursos fiscais para a composição do superávit primário e, por conseqüência, a sua utilização em pagamentos de juros da dívida. 
Logo, Marques; Mendes (2005) afirmam ser falacioso o discurso mobilizador do governo da existência de déficit na Previdência, haja vista que se não houvesse a "fuga" de recursos pela DRU, teríamos superávit do orçamento da Seguridade Social de R \$26,64 bilhões, em 2000; 31,46 bilhões, em 2001 e 32,96, em 2002. Somente em 2006, o resultado positivo da Seguridade Social foi em torno de R \$ 14 bilhões, mesmo após a retirada da DRU. Em 2007 foram despendidos cerca de $\mathrm{R} \$ 160$ bilhões com juros da dívida, valor correspondente a 3,5 vezes o gasto do Ministério da Saúde (MS) em ações e serviços públicos de saúde, que foi de $\mathrm{R} \$ 45$ bilhões.

Como uma tentativa de destinar mais recursos para a saúde, em 1996, foi aprovada a Contribuição Provisória sobre Movimentação Financeira (CPMF), e implantada pelo Ministro da Saúde, à época Adib Jatene, em 1997, cujo objetivo era superar a carência de recursos federais para a saúde que, com o passar do tempo, assumiu o papel de fonte substitutiva, passando por um processo de redistribuição; o que antes era exclusivo para a saúde, passou a ser partilhada com a Previdência Social, em 1999, e com o Fundo de Combate e Erradicação da Pobreza, em 2001.

Dain (2007) chama a atenção para o fato de que a CPMF não gerou o esperado incremento de recursos para a saúde à medida que foi acompanhada pela substituição das fontes reduzindo a importância da Contribuição sobre o Lucro Líquido (CSLL) e da COFINS na composição do orçamento do Ministério da Saúde. Ressalta-se que, em 1999, a CPMF deixou de ser fonte de financiamento exclusiva da saúde, passando a compor o financiamento das despesas previdenciárias e, dois anos mais tarde, passa a compor também o Fundo de Combate à Pobreza (BOSCHETTI; SALVADOR, 2006).

As duas instituições que vêm realizando análises sobre a estrutura orçamentária da Seguridade Social, a Associação Nacional dos Fiscais da Receita Federal do Brasil (ANFIP) e o Instituto de Pesquisa Econômica Aplicada (IPEA), apesar de utilizarem 
metodologias diferenciadas de análise, afirmam que a seguridade social é superavitária, sendo possível não somente cobrir as despesas das três políticas, mas, sobretudo, ampliá-las, sendo a DRU e sua destinação ao superávit primário o seu principal impeditivo.

\section{Em busca da legalidade da vinculação de recursos para saúde - percurso da $\mathrm{EC} \mathrm{N}^{\circ} .29$}

Durante alguns anos, a discussão em torno do financiamento da saúde foi crescendo, sem contudo chegar ao plenário no Congresso, pois não havia certeza de contar com sua aprovação (CARVALHO, 2008). Somente após seis anos, desde a apresentação da PEC Nº 169 na Câmara de Deputados, pelos Deputados Eduardo Jorge e Waldir Pires, em 1993, e sua aglutinação com a PEC Nº. 86, de autoria do Deputado Carlos Mosconi, em 1995, é aprovada a Emenda Constitucional $N^{\circ} .29$ (EC Nº. 29), em 13/09/2000, que vincula recursos para a saúde nas três esferas de governo, de forma progressiva até o ano de 2004 e estabelece percentuais mínimos de participação das receitas dos estados e dos municípios em 7\%, a partir do ano de sua implantação. No caso dos estados e municípios, a destinação deveria crescer anualmente até atingir de 12 e $15 \%$,respectivamente, do produto da arrecadação dos impostos e transferências constitucionais. No caso da União, o orçamento do Ministério da Saúde do ano de 2001 a 2004, seria apurado no ano anterior, corrigido pela variação nominal do Produto Interno Bruto (PIB).

Dessa forma, a EC $N^{\circ} .29$ representa uma importante conquista de setores da sociedade civil para consolidação do SUS, uma vez que estabelece a vinculação de recursos nas esferas estadual e municipal de governo para o financiamento estável do SUS, além de prever sanções no caso de descumprimento dos limites mínimos previstos na emenda. 
A regulamentação do novo texto constitucional deveria ser feita através de Lei complementar, o que resultou em um longo processo de tramitação. Sob a responsabilidade do Poder Legislativo, as negociações para a elaboração da Lei foram conduzidas, desde 2001, pelo próprio Ministério da Saúde, que tem como principal interlocutor o Conselho Nacional de Saúde (CNS). Esta luta também foi encampada por outros órgãos, com destaque para os conselhos de Secretários Estaduais de Saúde (CONASS) e de Secretários Municipais de Saúde (CONASEMS), os conselhos municipais e estaduais de saúde, a Comissão de Seguridade Social da Câmara Federal, a Comissão de Assuntos Sociais do Senado e a Associação dos Membros dos Tribunais de Contas (ATRICON) (FAVARET, 2003).

Nessa direção, a implantação da Emenda Constitucional Nº.29 sofreu diferentes interpretações pela indefinição do que são despesas com ações e serviços públicos de saúde, e por não especificar as fontes de receitas federais e a base de cálculo (BRASIL, 2005). A falta da regulamentação do texto da emenda vem permitindo que gestores não a cumpram ou que, para atingir os percentuais obrigatórios, atribuam ao setor gastos que não se relacionam, necessariamente, aos serviços e às ações de promoção, prevenção e recuperação da saúde.

A luta do SUS por recursos permanece incessante mesmo após a eleição do governo Lula. Segundo Marques; Mendes (2007) mesmo reproduzindo a agenda da saúde em seu "Programa de Governo 2002", o governo Lula, no empenho de produzir superávit primário, fez várias tentativas de redução de recursos para o orçamento da saúde pública.

No primeiro mandato, representantes do governo indicavam a aplicação de mecanismos como a DRU para estados e municípios, o que implicaria redução de recursos para a saúde nestas esferas de governo. Esta proposta só foi retirada mediante pressão contrária manifestada. Ainda em 2003, o governo Lula demonstra a intenção de flexibilizar os recursos vinculados (educação e saúde) sob alegação de que tal flexibilização poderia assegurar o crescimento do país. 
Para ter uma idéia, em 2004 e 2005, respectivamente foi retirado do orçamento do Ministério da Saúde um percentual de 2,70\% e 6,26\% que foram gastos com o programa de Transferência de Renda com Condicionalidades, o Bolsa Família, executado pelo Ministério do Desenvolvimento Social. Em 2005, o Bolsa Família ocupou o quarto lugar na participação do Fundo Nacional de Saúde (FNS), recebendo mais prioridade que programas tradicionais do SUS, a exemplo da Vigilância Epidemiológica e Ambiental (2,31\%), Vigilância, Prevenção e Atenção em HIV/AIDS e outras Doenças Sexualmente Transmissíveis (2,16\%) e Atenção à Saúde da Mulher (0, 001\%) (BOSCHETTI; SALVADOR, 2006).

No sentido de equacionar tais indefinições, o Conselho Nacional de Saúde (CNS) aprovou a Resolução Nº.322/2003, definindo as diretrizes acerca da aplicação da EC N $N^{\circ} .29$ e a base de cálculo para o financiamento e determinando o que é e o que não é considerado como despesa com ações e serviços públicos de saúde ${ }^{3}$. Para esta Resolução alcançar força de Lei, tramita na

3 Para efeito da aplicação da Emenda Constitucional n ${ }^{\circ} .29$ consideram-se despesas com ações e serviços públicos de saúde aquelas com pessoal ativo e outras despesas de custeio e de capital, financiadas pelas três esferas de governo, conforme o disposto nos artigos 196 e 198, \$ $2^{\circ}$, da Constituição Federal e na Lei n 8080/90, relacionadas a programas finalísticos e de apoio, inclusive administrativos, que atendam, simultaneamente, aos seguintes critérios:

I - sejam destinadas às ações e serviços de acesso universal, igualitário e gratuito;

II - estejam em conformidade com objetivos e metas explicitados nos Planos de Saúde de cada ente federativo;

III - sejam de responsabilidade específica do setor de saúde, não se confundindo com despesas relacionadas a outras políticas públicas que atuam sobre determinantes sociais e econômicos, ainda que com reflexos sobre as condições de saúde.

$\int$ Único - Além de atender aos critérios estabelecidos no caput, as despesas com ações e serviços de saúde, realizadas pelos Estados, Distrito Federal e Municípios deverão ser financiadas com recursos alocados por meio dos respectivos Fundos de Saúde, nos termos do Art. 77, $\ 3^{\circ}$ do Ato das Disposições Constitucionais Transitórias (ADCT) (BRASIL, 2003, p. 10-11). 
Câmara Federal o Projeto de Lei Complementar (PLC) 01/03, de autoria do Deputado Roberto Gouveia (PT-SP), que mantém os mesmos percentuais de aplicação mínima para estados e municípios. Para a União fixa a obrigatoriedade da aplicação mínima de 10\% das receitas correntes brutas do Orçamento Fiscal e da Seguridade Social.

A segunda investida do governo Lula contra a saúde, mesmo depois de o MS ter ratificado a Resolução $N^{\circ} .322$ do Conselho Nacional de Saúde (CNS), de maio de 2003, que definia ações e serviços públicos em saúde, foi que a equipe econômica tentou fazer "passar" como gasto em saúde o pagamento de juros e a aposentadoria dos funcionários desse Ministério. Se não fosse a mobilização do Fórum da Reforma Sanitária (Abrasco, Cebes, Abres, Rede Unida e Ampasa), do CNS e da Frente Parlamentar da Saúde (FPS), essas tentativas, muito provavelmente, teriam ido a termo.

A resistência do Governo, sobretudo dos Ministérios da área econômica, para aprovação deste projeto, deve-se ao fato do mesmo contrariar as recomendações neoliberais do Fundo Monetário Internacional (FMI) e do Banco Mundial (BM), que orientam a desvinculação de todos os recursos do orçamento para que fiquem liberados para a amortização dos juros da dívida e outras despesas. Como afirma Conceição Rezende (2008, p. 8):

Enquanto o Governo prioriza os Bancos Multilaterais, a globalização e o pagamento da dívida externa em detrimento do povo brasileiro, a EC 29 é o que temos por causa da nossa luta! A sensação de regulamentá-la (de nossa parte) é porque gastamos tempo e munição de guerra. Apenas para vencer uma rixa... ou, se preferir, uma rusga... pois são públicas e notórias as necessidades de mais recursos financeiros para o Setor Saúde no Brasil. 
Fruto do contingenciamento dos recursos por parte do Governo Federal, o Ministério do Planejamento anunciou, para o ano de 2007, um bloqueio de $\mathrm{R} \$ 16,4$ bilhões, do que estava previsto no Orçamento Geral da União. Desta verba contingenciada, $46 \%$ correspondia à área social. As despesas para as políticas sociais (saúde, assistência social, educação, saneamento, entre outras) estavam previstas em $\mathrm{R} \$ 65,1$ bilhões e passaram a ser $\mathrm{R} \$ 57,4$ bilhões. O principal corte foi no Ministério da Saúde, que teve um orçamento diminuído de $\mathrm{R} \$ 40,6$ bilhões para $\mathrm{R} \$ 34,8$ bilhões. (ORÇAMENTO..., 2007).

Em 2007, a cobrança da Contribuição Provisória sobre Movimentação Financeira não foi prorrogada pelo Congresso Nacional, sendo extinta em 31/12/2007. Para compensar parcialmente as perdas de arrecadação, o Governo Federal editou os Decretos $\mathrm{N}^{\circ} .6 .339$ e 6.345 , elevando as alíquotas do imposto sobre operações financeiras (IOF), ou seja, de crédito, câmbio e seguro.

Depois de várias tentativas fracassadas, a Emenda Constitucional $N^{\circ} .29$ foi regulamentada em 2008, no Senado Federal, aguardando apenas a aprovação na Câmara de Deputados. Convém destacar que, o avanço da aprovação desta emenda não reside somente na vinculação dos recursos, mas também na responsabilização dos entes federados com o financiamento do SUS.

O Deputado Pepe Vargas sugeriu, através do Projeto de Lei Complementar 306B/08, a regulamentação da EC 29 acrescida de artigos que prevêem a criação de uma fonte complementar direcionada à saúde, a Contribuição Social para a Saúde (CSS), com alíquota de $0,1 \%$ sobre movimentações financeiras. A polêmica gira em torno da substituição da CPMF, revogada em 2007, uma vez que esta também fora criada com o mesmo intuito da CSS, mas acabou por ser também fonte de financiamento para outros setores que não a saúde. O PLC 306B/08 foi aprovado pelo Plenário da Câmara dos Deputados, em 11 de junho de 2008, prevendo uma arrecadação de $\mathrm{R} \$ 11,8$ bilhões, para 2009 , e sua votação foi encaminhada ao Senado. 
É importante ressaltar que se considerado o que estava previsto inicialmente no Ato das Disposições Constitucionais Transitórias da CF/1998, os recursos do Ministério da Saúde disponibilizados para o ano de 2008 seriam da ordem de $\mathrm{R} \$ 120$ bilhões, entretanto, a aprovação da Emenda Constitucional N ${ }^{\circ} .29$ foi num contexto político-econômico de retração estatal, sobretudo para o financiamento de políticas públicas garantidoras de direito, sendo necessário elucidar a adequação do gasto.

Nesse sentido, convém retomar a proposta da descentralização pensada na CF/1988 como um dos princípios organizativos do Sistema Único de Saúde (SUS), um dos conceitos que apóia nossa análise, compreendida aqui como a transferência de poder, recursos e autonomia, é atualmente umas das importantes vias de efetivação da democratização do Estado. Em termos conceituais, refere-se à "transferência ou delegação de autoridade legal e política aos poderes locais para planejar, tomar decisões e gerir funções públicas do governo central" (JACOBI, 1993, p. 35).

Ressalte-se, porém, que a descentralização que vem ocorrendo no país é caracterizada apenas pela delegação de competências, sem, portanto, deslocamento do processo decisório, sobretudo numa conjuntura de recentralização de recursos por meio da Desvinculação de Recursos da União, que subtrai recursos do orçamento da seguridade e, consequentemente, as transferências Fundo a Fundo das Políticas de saúde e assistência social.

Não podemos compreender o SUS isolado do conjunto da política social e econômica, mas tratá-lo como política estruturante na garantia dos direitos sociais, sendo imprescindível sua sustentabilidade. Tivemos até então avanços parciais no campo do financiamento, embora este nos últimos anos venha sofrendo vários ataques de desmonte das conquistas alcançadas no plano jurídico-legal. 
Considerando que gasto em saúde não é sinônimo de desperdício de recursos, todos os envolvidos com a formulação, planejamento, gestão e controle da política de saúde devem zelar pela qualidade do seu gasto reivindicando do SUS o direito ao financiamento suficiente e sustentável como forma de honrar seu compromisso junto à população brasileira, materializando a saúde como direito social universal, portanto garantido pelo Estado.

\section{O cumprimento da Emenda Constitucional No. 29 - análise e perspectivas}

O acompanhamento do cumprimento da Emenda Constitucional $N^{\circ} .29$ (EC 29) é realizado pelo Sistema de Informações sobre Orçamentos Públicos em Saúde (SIOPS), criado em 2000, cujo objetivo é a coleta os dados de receitas totais e despesas em saúde de estados e municípios. As informações coletadas pelo SIOPS são obtidas a partir de dados contábeis ou de informações dos relatórios e demonstrativos de execução orçamentária e financeira dos governos estaduais, distrital e municipais (SIOPS, 2009). Assim, este sistema tem a credibilidade de ser o instrumento de acompanhamento da aplicação dos recursos vinculados em ações e serviços públicos de saúde.

O cumprimento da EC 29 é, ainda, um desafio a ser perseguido pela totalidade de estados e municípios. Conforme se pode ver no quadro 1, segundo dados do SIOPS, em 2009, dos 27 estados (incluindo Distrito Federal), 24 atingiram o mínimo constitucional. Apenas três estados não aplicaram tal percentual. 


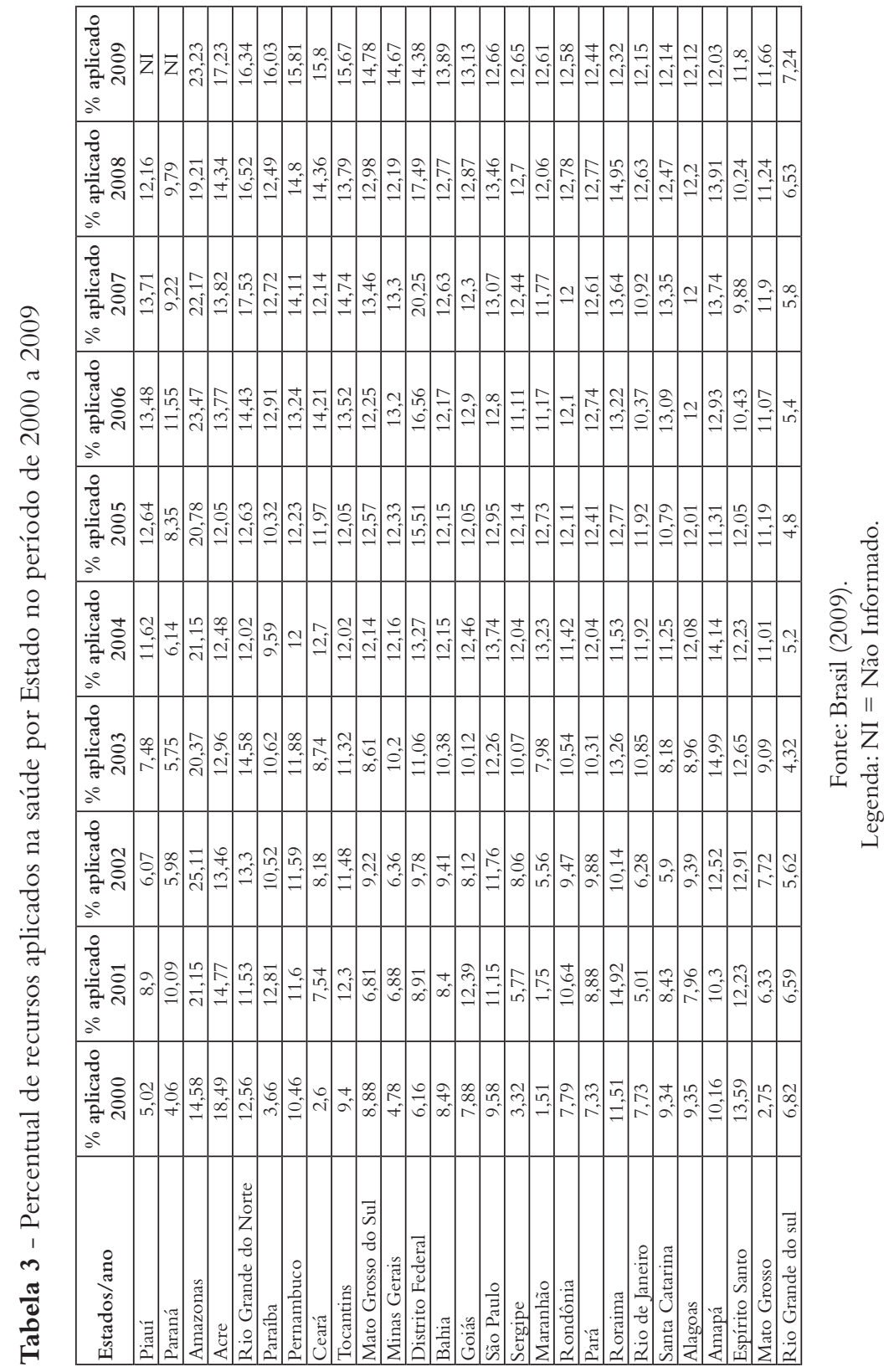


Tais números significam um claro avanço. Em 2000, apenas quatorze estados cumpriram a emenda $(48,15 \%$ do total de estados). Naquele ano, quatro estados não enviaram suas informações ao SIOPS. Desde então, se vê uma evolução considerável, especialmente a partir do momento em que o não cumprimento ou não envio dos dados começou a significar a reprovação das contas junto ao Tribunal de Contas dos Estados.

Gilson Carvalho, sanitarista, especialista em financiamento da saúde, em 2000, já expressava sua preocupação com possíveis retrocessos, a partir da entrada em vigor da EC-29 para estados que naquele momento estivessem acima dos 12\% mínimos. Felizmente, também neste aspecto, as notícias foram boas. Apenas o estado do Espírito Santo recuou, pois em 2000 já investia 13,59\%, apresentando em todos os anos posteriores percentuais inferiores, chegando a 2009 com 11,8\%. O melhor caso é o do estado do Amazonas que, em 2000, investia $14,58 \%$, apresentando percentuais interessantes de investimentos, tendo como pico de 25,11\% em 2002, mas ainda com bom desempenho em 2009 quando investiu 23,23\%.

Após a implementação da Emenda, os estados que pouco investiam na saúde, a exemplo do Rio de Janeiro, Paraná, Minas Gerais, Piauí e Paraíba ampliaram seus gastos neste setor. Os casos mais gritantes foram do Maranhão (com incrível percentual de 1,51\% em 2000 e o cumprimento do mínimo a partir de 2008) e Ceará (de 2,60\% em 2000 para o pleno cumprimento do mínimo a partir de 2006). Os estados do Paraná e Piauí ainda não passaram as suas informações para o SIOPS, o que impossibilita a análise para o ano de 2009.

Entre os destaques negativos, o caso do Rio Grande do Sul chama a atenção. O Estado chegou, em 2007, a obter percentual menor do que tivera em 2000. Em 2009, investiu apenas 7,24\%. Em nenhum dos anos conseguiu cumprir a EC-29. O estado do Paraná é outro com baixos índices, porém em franca expansão: saiu de 4,06\%, em 2000, para 9,79\%, em 2008, após o quase 
cumprimento em 2006, quando chegou a 11,55\%. Em 2009, o governo do estado não repassou as informações para o SIOPS. Segundo Carvalho (2009), em 2006, os estados ficaram devendo $\mathrm{R} \$ 3,4$ bilhões ao sistema, enquanto os municípios gastaram $\mathrm{R} \$ 6$ bilhões a mais com saúde. Entre 2000 a 2006, a dívida dos estados foi de $\mathrm{R} \$ 20$ bilhões. "Deram um rombo à luz do dia", afirmou Carvalho (2009, p. 21).

Se a preocupação de Gilson Carvalho quanto a possíveis reduções dos percentuais por parte dos estados e municípios já cumpridores não se realizou, outros alertas do referido autor podem estar sendo concretizados.

Primeiro, se no corpo da EC-29 houve clara preocupação com a definição sobre quais itens são gastos com saúde, nem sempre tal aplicação foi consensual nos estados e nos Tribunais de Contas dos Estados.

O próprio SIOPS passa a aceitar justificativas, muitas vezes em contradição com o Tribunal de Contas dos Estados. O caso da Paraíba é exemplar. Segundo os atuais dados do SIOPS o referido estado teria passado de 3,66\% em 2000 para 12,81\% em 2001. Nos anos seguintes, apesar de certa queda, o estado manteve percentuais razoáveis, respectivamente 10,52\%, 10,62\%, 9,59\%, 10,32\%, $12,91 \%, 12,71 \%, 12,49 \%$ e 16,03\% nos anos de 2002, 2003, 2004, 2005, 2006, 2007, 2008 e 2009. Por esses dados, o estado da Paraíba apenas não teria cumprido os percentuais mínimos em 2000, 2004 e 2005. Chama a atenção o importante salto verificado em 2009.

O mesmo SIOPS divulgava, em outros momentos, dados diferentes. No período 2000-2003, os dados anuais eram respectivamente de 4,41\%,12,82\%,11,29\% e 7,83\%. O ano de 2003 era, portanto, de não cumprimento.

Embora se saiba que é preciso revisar o que, por algum motivo, não foi processado corretamente, as sucessivas revisões dos percentuais mínimos informados podem significar a perda de 
credibilidade das próprias informações do SIOPS. Ao promover a revisão na Paraíba, os dados do SIOPS entraram em conflito com os do Tribunal de Contas do Estado, que trabalha com a informação de que o estado não cumpriu o percentual mínimo para a saúde, embora tenha aprovado as contas do gestor.

Outra preocupação de Carvalho (s/d) era com relação ao maior comprometimento de responsabilidades da parte de estados e municípios, sem que houvesse uma descentralização de recursos. De fato, segundo o SIOPS, a participação da União com Despesas com Ações e Serviços Públicos de Saúde caiu nos últimos anos de 1,73\% do PIB, em 2000, para 1,68\%, em 2004, tendo chegado a 1,60\%, em 2003. Em 2005, porém, recupera o percentual de 1,73\%. A participação dos estados aumenta de 0,54\% do PIB para 0,80\% no mesmo período, tendo chegado a 0,83\%, em 2004. A participação dos municípios salta de $0,63 \%$ do PIB para $0,94 \%$ no mesmo período.

É importante observar que a EC 29, nas palavras de Marques; Mendes citados por Campelli; Calvo (2007, p. 1617), "não chega a resolver o problema da insuficiência de recursos da área e tampouco sua relação com as diversas fontes da seguridade". Isto posto, o aumento das participações de estados e municípios não se constitui por si só um problema, mas antes significa mais recursos para atenderem demandas potenciais ilimitadas.

O fato de, em 2009, 22 dos 27 estados (81,14\% do total) terem cumprido o percentual não significa por si só que a luta por mais recursos para a saúde tenha acabado. Primeiro, porque ainda três estados não cumpriram (11\%) e dois sequer informaram os seus dados ao SIOPS $(7,4 \%)$. Segundo, porque poucos estados se aventuraram a investir muito mais que os $12 \%$ previstos em lei. Terceiro, porque o cumprimento do percentual mínimo não garante, mesmo com os critérios sobre o que são gastos com saúde na própria emenda, a qualidade dos gastos realizados. 
Ao mesmo tempo, a União não tem cumprido a EC-29. Campelli; Calvo (2007) calculavam que entre 2001 e 2003, a União deixou de investir cerca de $\mathrm{R} \$ 1,8$ bilhão. Em tempos de aumento do crescimento do PIB, tal hiato tende a ser maior. A partir da revisão metodológica do cálculo do PIB, anunciada pelo IBGE, em 2007, certamente tal diferença tende a crescer, uma vez que os percentuais de crescimento do PIB, em sua maioria, foram recalculados para cima.

Entretanto, Carvalho (s/d; s/p) adverte que:

A finalidade da PEC era conseguir mais recursos para a saúde. Quem mais tem que contribuir é exatamente a União, pois é a única esfera de governo que arrecada diretamente contribuições sociais para garantir saúde, previdência e assistência social. Estados e Municípios vão retirar de suas receitas gerais. A União abocanha cerca de $56 \%$, Estados $28 \%$ e Municípios $16 \%$ de tudo que se arrecada de impostos e contribuições.

Portanto, ainda lembra o autor, por mais que se aumente a alíquota de estados e municípios, a repercussão financeira será pouco significativa, já que a arrecadação é majoritária da União, devendo ser a mais onerada, pois ela arrecada para isto, o que é impróprio a estados e municípios.

Esta lógica de liberação de recursos da União com liberdade alocativa faz parte da recomendação dos organismos internacionais, ao qual o governo Lula vem dando seguimento, mantendo a hegemonia do capital financeiro já que, segundo Druck; Filgueiras $(2007,27)$,

o governo Lula não moveu um milímetro para alterar a essência do modelo de desenvolvimento - caracterizado, sobretudo, pela dominação da lógica financeira - nem, tampouco, a política macroeconômica que herdou do governo anterior. 
Nesse sentido, torna-se importante levar em consideração o critério da base móvel no cálculo do mínimo a ser aplicado pelo Governo Federal. Pelo critério da base móvel, defendido pelo Conselho Nacional de Saúde, Ministério da Saúde e Tribunal de Contas da União, a base para o cálculo será sempre a do ano anterior. Desta forma, se tem o crescimento anual do PIB. Pela base fixa, a base seria o volume mínimo de recursos calculado para o ano anterior, ou seja, considera como base apenas os valores mínimos definidos na Emenda para o ano em questão. Assim sendo, pelo critério da base fixa os valores a serem aplicados são menores que na outra proposta Exatamente por isto, esta é a proposta defendida pelo Ministério da Fazenda.

Trata-se, portanto, sob o ponto de vista da sociedade organizada, de um momento de ainda buscar que a totalidade dos estados e municípios cumpra o previsto em lei.A luta se mantém. Ao mesmo tempo, é importante desenvolver instrumentos para acompanhar a qualidade dos gastos.

\section{Considerações finais}

Sendo o financiamento da seguridade social seu ponto mais vulnerável, a desestruturação do OSS se constitui um dos elementos para inviabilizar a sua materialização (BOSCHETTI; SALVADOR, 2006).

O setor saúde e suas necessidades, tão bem conhecidas pela população, vêm sendo utilizados como justificativa para a crescente arrecadação de impostos, sem que, em seguida, se utilizem destes recursos, a exemplo do aumento do valor da alíquota da contribuição de empregados de 6 para 9\%; do aumento do COFINS (anteriormente denominado FINSOCIAL) de 0,5\% para 2\%; da criação da CSLL; da criação da CPMF, não destinada integralmente à saúde e, principalmente, da subtração de receitas de estados e municípios, através da DRU, para aumentar a receita central da união (CARVALHO, 2008). 
Para aqueles que supunham que a EC $\mathrm{N}^{\circ} .29$ pudesse promover a blindagem do sistema, a nosso ver, o seu cumprimento, embora seja capaz de ampliar os recursos para a saúde, não permite cumprir o dito constitucional da saúde como direito de todos e dever do Estado, pois a soma dos gastos públicos com saúde nas três esferas de governo, em 2007, foi de R $\$ 94,4$ bilhões, enquanto o gasto privado foi de $\mathrm{R} \$ 98,4$ bilhões, totalizando $\mathrm{R} \$ 192,8$ bilhões para a saúde. O custo público da saúde por pessoa, naquele ano foi de $\mathrm{R} \$ 1,41$ por dia (CARVALHO, 2009). Disto comprova-se que o financiamento da saúde ainda é incompatível com a ampliação e universalização dos direitos sociais.

Se por um lado a Emenda Constitucional é um importante passo para a estabilidade financeira na saúde, por outro, medidas contundentes de ajustes vêm sendo tomadas, as quais coadunam mais com a lógica securitária e mercadológica da saúde que com a garantia da saúde como direito universal.

Fica patente, nesse contexto que a priorização da política econômica neoliberal pelos governos desde a década de 1990 e mantida pelo governo atual não só impossibilita um crescimento sustentável, como impede o financiamento para as áreas sociais, principalmente da Saúde. Sendo assim, a luta continua! 


\section{Referências}

A SAÚDE pública no centro de um mundo em crise. Radis, Rio de Janeiro, $n^{\circ} .76$, p. 14-31, dez. 2009.

ANDREAZZI,M, F. S.; OCKÉ-REIS, C. O;. Renúncia de arrecadação fiscal: subsídios para discussão e formulação de uma política pública.

PHYSIS: Rev. Saúde Coletiva, Rio de Janeiro, v. 17, n. 3, p. 521-544, 2007.

ANFIP. Análise da Seguridade Social em 2006. Fundação Anfip de Estudos de Seguridade Social. Brasília, Anfip, 2007. Disponível em <www.anfip.org.br> Acesso: 30 maio 2007.

ANFIP. Análise da Seguridade Social em 2007. Fundação Anfip de Estudos de Seguridade Social. Brasília, Anfip, 2008. Disponível em <www.anfip.org.br> Acesso em: 10 jan. 2009.

ANFIP. Análise da Seguridade Social em 2008. Fundação Anfip de Estudos de Seguridade Social. Brasília, Anfip, 2009. Disponível em <www.anfip.org.br> Acesso em: 10 mai 2009.

BERING, E. R. Brasil em contra-reforma: desestruturação do Estado e a perda de direitos. São Paulo: Cortez, 2003.

BERING, E. R; BOSCHETTI, Política social: fundamentos e história. São Paulo Ed. Cortez, 2006.

BOSCHETTI, I.; SALVADOR, E. Orçamento da seguridade social e política econômica: perversa alquimia. Serviço Social e Sociedade, n. 87, São Paulo: Cortez, 2006.

BRASIL. Constituição da República Federativa do Brasil. Brasília, DF: Senado Federal, 1988.

BRASIL. Ministério da Saúde. Sistema de Informação sobre Orçamentos Públicos em Saúde (SIOPS). Disponível em: www. datasus.gov.br. Acesso em 15 jan. 2009. 
CAMPELLI, M. G. R; CALVO, M. C. O cumprimento da Emenda Constitucional N. 29. Cadernos de Saúde Pública, Rio de Janeiro: julho de 2000 .

CARVALHO, G. Gasto com Saúde no Brasil em 2007. IDISA, 2008.

CARVALHO, G. O. Expressão Reducionista. RADIS, Rio de Janeiro, n. 77, jan. 2009.

CRUZ, F. F; DAVI, J; DANTAS, M. F. M. O financiamento da Assistência Social no contexto do Sistema Único da Assistência Social: um estudo sobre a realidade dos municípios de pequeno porte II habilitados na gestão plena do estado da Paraíba. 2008. 50 f. Relatório Parcial (PROINCI). Departamento de Serviço Social. Universidade Estadual da Paraíba. Campina Grande, 2008.

DAIN, S. Os vários mundos do financiamento da Saúde no Brasil: uma tentativa de integração. Ciência e Saúde Coletiva, v. 12 (sup), p. 1851-64, 2007.

DRUK, G.; FILGUEIRAS, L. Política Social focalizada e ajuste fiscal: as duas faces do governo Lula. Revista Katálysis. Florianópolis, v. 10, n. 1, p. 15-23, jan./jun. 2007.

JACOBI, P. Estado e movimentos sociais: algumas questões controversas. In: . Movimentos sociais e políticas públicas: demandas por saneamento básico e saúde em São Paulo 1974-1984. 2ª ed. São Paulo: Cortez, 1993.

MARQUES, R. M; MENDES, A. Os dilemas do financiamento do SUS no interior da Seguridade Social. Revista Economia e Sociedade. Campinas, v. 14, n. 1, p. 159-175, 2005.

MARQUES, R. M; MENDES, A. Servindo a dois senhores: as políticas sociais no governo Lula. Revista Katálisys. Florianópolis. v. 10, n. 1. p. 15-23, jan./jun. 2007. 
MOTA, A. E. Cultura da crise e seguridade social: um estudo dobre as tendências da previdência e da assistência social brasileira nos anos 80 e 90. São Paulo: Cortez, 1995.

MOTA, A. E. Seguridade social no cenário brasileiro. In. CONGRESSO BRASILEIRO DE ASSISTENTES SOCIAIS, 11., 2004, Fortaleza. Anais... Fortaleza, 2004.

MOTA, A. E. Serviço Social e seguridade social: uma agenda recorrente e desafiante. Revista Em Pauta, Rio de Janeiro, nº. 20, 2007.

ORÇAMENTO da saúde 2007. R \$ 5,7 bilhões a menos. Radis, Rio de Janeiro, $n^{\circ} .55$, mar. 2007.

REZENDE, M. C. Nota técnica: A implementação da Emenda Constitucional 29 (Emenda Da Saúde). Disponível em: www.pt.org.br. Acesso em 18/01/2009.

SOARES, L.T. R. Ajuste Neoliberal e desajuste social na América Latina. Rio de Janeiro:Vozes, 2001. 